\title{
PRODUÇÃO DE TEXTO NA ESCOLA: UMA PRÁTICA DIALÓGICA
}

Janete Silva dos Santos*

RESUMO: O presente texto é um resgate de uma experiência bem sucedida no ensino de produção de texto para uma clientela de ensino fundamental ( $5^{\mathrm{a}}$ a $7^{\mathrm{a}}$ séries), durante nossa atuação naquele nível. Todavia, aproveitamos a ocasião para discutir alguns pontos da aparente mudança de foco quanto ao ensino de produção de texto na escola hoje. Julgamos válido apresentar o que ficou de positivo desse trabalho, bem como refletir se estamos mudando efetivamente de atitude no tocante a essa atividade, à luz da teoria de Bakhtin (entre outros), o qual vê a linguagem como uma prática dialógica.

PALAVRAS-CHAVE: Produção de texto, Dialogismo, Ensino.

ABSTRACT: The present text is well a ransom of an experience happened in the teaching of text production for a clientele of fundamental teaching ( 5 th to 7 th series), during our performance in that level. Though, we profited the occasion to discuss some points of the apparent focus change with relationship to the teaching of text production in the nowadays school. We judged valid to present what was positive of that work, as well as to contemplate if we are changing indeed of attitude concerning that activity, to the light of the theory of Bakhtin (among other), which sees the language as a dialogic practice.

KEY WORDS: Text production, Dialogism, Teaching. 
* Prof ${ }^{a}$ Mestrenda Universidade Federal de Tocantins - UFT

\section{INTRODUÇÃO}

A produção de texto na escola vem sendo o foco da preocupação de professores, psicolingüistas e educadores em geral, numa escala cada vez maior, haja vista ser uma das metas da educação formal desenvolver no aluno, entre outras competências, a prática da comunicação escrita. Isso vem aflorando exatamente porque o alcance de tal meta tem sido uma das maiores dificuldades das instituições escolares. Contudo, pesquisas e artigos de estudiosos envolvidos com o assunto têm contribuído não apenas para a reflexão, como também para redimensionar posições teóricas, metodologias e técnicas que corroborem ou efetivem a prática da produção de texto não como uma atividade artificial, mas como uma atividade motivada por um sujeito que se assuma, ou se pretenda, como autor do texto.

Considerando os caminhos pelos quais as investigações vêm percorrendo, julgamos interessante contribuir com o debate, levando em conta nossa experiência como professora de ensino fundamental, trabalhando seqüencialmente com praticamente os mesmos alunos na $5^{\mathrm{a}}, 6^{\mathrm{a}}$ e $7^{\mathrm{a}}$ séries, nos anos de 1996 a 1998, respectivamente, trabalho que nos deu muita satisfação. Nessa contribuição, entendemos ser relevante apresentar apenas o como nos conduzíamos em situações que envolviam a prática de produção de texto por parte de nossos alunos. Nossa inquietação surge, também, por percebermos que, apesar de todo o esforço, muitos de nós ainda andam em círculo no tocante à concepção/ prática do que seja, de fato, o trabalho de produção de texto para o autor-aluno.

Nosso posicionamento parte do princípio de que só participamos de um bate-papo com interesse se houver a retroalimentação por parte de nosso interlocutor. E isso havendo temos a oportunidade de aperfeiçoar nossa competência. Se na oralidade isso é tão real quanto à existência do ar que nos mantém vivos e se a troca enunciativa, nessa modalidade, visa à efetivação 
comunicativa, na produção escrita não é diferente. É deste diálogo que nos ocuparemos no decorrer de nossa discussão, a qual terá como suporte teórico básico o dialogismo bakhtiniano.

\section{ANTES ERA A COMPOSIÇÃO}

Houve uma época de nossa vivência escolar em que, na disciplina Comunicação e Expressão, éramos incitados a compor um texto para a(o) professora(o), a(o) qual verificava semanal ou mensalmente se estávamos progredindo no domínio da arte de escrever - talvez porque compor tenha a conotação de trabalho de artista - mas, e principalmente, verificava se estávamos progredindo no dominio das regras da língua. É justo destacar que, nesse tempo, durante algumas datas especiais o aluno fazia o papel de autor do escrito quando era solicitado a escrever, sob orientação da(o) professora(o), uma cartinha ou um cartão para a mãe, o pai, o avô ou avó, o tio ou a tia, ou para o Papai Noel, quer no dia dos dois primeiros, quer no Natal, entre outras comemorações, acreditando o aluno ter um interlocutor verdadeiro que reagiria aos efeitos de seu dizer, manifestando uma atitude que lhe sinalizaria retorno da mensagem enviada.

\section{DEPOIS VEIO A REDAÇÃO}

Entendeu-se, no decurso, que redigir era o verbo mais apropriado para as tarefas escriturárias, e com ele o substantivo redação virou lugar comum, de tal maneira, que nem professores e pesquisadores o suportariam mais, pois a palavra redação por si só passou a abarcar toda a angústia da dificuldade e artificialidade de escrever. O texto do aluno, como é sabido, servia prioritariamente de instrumento para se verificar o conhecimento ortográfico e o domínio do uso adequado da pontuação e concordância, avançando para a verificação da capacidade do aluno em não fugir ao tema proposto (imposto), pouco importando o que o aluno pensava ou dominava efetivamente sobre tal tema, ou se estava motivado para desenvolvê-lo. A correção por parte do professor, numa pesquisa 
de Eliana Ruiz (2001, p. 48) "consiste, dessa forma, no trabalho de marcar no texto do aluno as possíveis "violações" lingüísticas nele cometidas contra uma suposta imagem do que venha a ser um bom" texto. Todavia, também é justo reconhecer que se trabalhou incansavelmente para proporcionar ao aluno motivos para escrever, através de dinâmicas de envolvimento com o tema: discussões, jogos, texto-estímulo etc..

\section{AGORA É A PRODUÇÃO DE TEXTO}

Com o tempo, evoluiu-se para a preocupação com a mensagem, na verdade, com a coesão e coerencia do texto, entre outros elementos que acusem textualidade, o que não difere, a nosso ver, do objetivo de se verificar a capacidade de se ser fiel a um tema proposto. Mas o diferencial das falas passou a ser a defesa de se acentuar o conteúdo sobre a forma, orientação que, também, já se ventilava na atividade de redação. Entretanto, hoje, procura-se defender a liberdade de expressão do aluno, a valorização de seu dižer, a quebra de padrões de escrita que inibem a autoria bem como anulam o desenvolvimento do estilo embrionário do aluno-autor. Defendese, assim, a produção de textos de gêneros variados, levando-se em conta, de maneira mais concreta, as diversas funções da linguagem, até o fato de que conteúdo e forma não estão dissociados, não sendo coerente, portanto, sobrepor -se um ao outro.

Nessa linha, o que vem tomando corpo como objeto de estudo e aplicação na sala de aula é o processo da produção de texto, da produção discursiva com suas tentativas de conjugar a estabilidade e a instabilidade da lingua (FIORIN, 1999), daí a valorização do como o aluno constrói um texto coeso, do como a coerência se apresenta em seu texto, do que interessa ao aluno dizer; fomenta-se, principalmente, o incentivo, mais ainda no ensino fundamental, a assunto de interesse público, de preferência que envolva o contexto imediato do aluno-autor. Por isso as várias empreitadas para se convencer o aluno de que é capaz de escrever, de que escrever é bom, evitandose, inclusive, devolver-lhe o texto pichado de sangue. Nesse novo 
contexto, muitos professores sentem-se até inibidos de apontar as incoerências do texto, causadas por quebra de regras básicas na comunicação escrita.

Sem dúvida, todo esse nosso esforço é válido e necessário, uma vez que tateamos caminhos mais promissores para a inculcação da escrita como competência lingüística necessária para a vida em sociedade letrada, competência lingüística na prática social de indivíduos que têm obrigação, pelos anos de vida acadêmica, de manifestar níveis satisfatórios de letramento nessa habilidade. Mas o que nos inquieta é que saltamos de um alvo para outro sem mudarmos o foco.

A questão parece paradoxal colocada nesses termos, porém, recuperando o princípio que propusemos na introdução deste texto, o dialogismo bakhtiniano, não cedemos, ainda, o devido lugar ao diálogo com o texto do aluno.

Bakhtin (1997) concebe a língua como um lugar de conflitos em busca de ajustes e um produto gerado e sustentado na (e pela) interação verbal, cujo objetivo precípuo é a troca enunciativa. A língua é vista, fundamentalmente, como a base da comunicação verbal, com todas as implicações que ela, elemento complexo, envolve. Ao discordar das posições de teóricos que defendem o processo comunicativo como a relação entre locutor e ouvinte, em que o primeiro tem uma fala ativa e o segundo uma percepção passiva, diz o autor (p. 290; 291):

... o ouvinte que recebe e compreende a significação (lingüística) de um discurso adota simultaneamente, para com este discurso, uma atitude responsiva ativa: ele concorda ou discorda (total ou parcialmente), completa, adapta, apronta-se para executar, etc., e esta atitude do ouvinte está em colaboração constante durante todo o processo de audição e de compreensão desde o início do discurso, às vezes já nas primeiras palavras emitidas pelo locutor. A compreensão de uma fala viva, de um enunciado vivo é sempre acompanhada de uma atitude responsiva ativa (conquanto o grau dessa atividade seja 
muito variável); toda compreensão é prenhe de resposta e, de uma forma ou de outra, forçosamente a produz: o ouvinte torna-se locutor.

Este destaca a impossibilidade de real inércia frente aos enunciados que nos são propostos, por mais que não manifestemos resposta imediata e na mesma freqüência que os recebemos, ao prosseguir dizendo:

A compreensão passiva das significações do discurso ouvido é apenas o elemento abstrato de um fato real que é o todo constituído pela compreensão responsiva ativa e que se materializa no ato real da resposta fônica subseqüente. Uma resposta fônica, claro, não sucede infalivelmente ao enunciado fônico que a suscita: a compreensão responsiva ativa do que foi ouvido (por exemplo, no caso de uma ordem dada) pode realizarse diretamente como um ato (a execução da ordem compreendida e acatada), pode permanecer, por certo lapso de tempo, compreensão responsiva muda (certos gêneros do discurso fundamentam-se apenas nesse tipo de compreensão, como, por exemplo, os gêneros líricos), mas neste caso trata-se, poderíamos dizer, de uma compreensão responsiva de ação retardada: cedo ou tarde, o que foi ouvido e compreendido de modo ativo encontrará um eco no discurso ou no comportamento subseqüente do ouvinte.

E esse dialogismo não fica apenas no que o autor classifica como gêneros primários, ou seja, os gêneros da comunicação verbal espontânea, que dão suporte ao surgimento dos gêneros secundários. É o que mostra na finalização do parágrafo em comento, ao esclarecer:

Os gêneros secundários da comunicação verbal, em sua maior parte, contam precisamente com esse tipo de compreensão responsiva de ação retardada. O que acabamos de expor vale também, mutatis mutandis, 
para o discurso [lido ou escrito].

O discurso lido ou escrito (grifo nosso) de que fala Bakhtin é o foco de nossa argumentação. $\mathrm{O}$ autor chama a atenção para o processo de troca enunciativa como uma prática de provocação mútua que dá sustentação, sentido e prosseguimento aos atos comunicativos.

O aluno provocado pelo professor a um diálogo oral na sala de aula, em geral, só se furta a participar visivelmente se for muito tímido, ou se não tiver o mínimo domínio sobre o assunto, ou se julgar o papo chato. Mesmo assim sua atitude de contenção ou indiferença, para Bakhtin, seria considerada uma atitude responsiva, responsiva muda ou de ação retardada.

Entendemos que, se o professor estivesse, de fato, pretendendo a participação manifesta imediata e concretamente de um aluno durante as discussões, a atitude descrita provavelmente poderia causar-lhe um certo desânimo ou frustração. Por outro lado, que professor experiente não percebe que certos alunos, ao se manifestarem, o fazem apenas para cumprir protocolo? Assim, o diálogo tende a morrer ou a tornar-se um faz-de-conta enfadonho.

Um texto escrito é uma proposta (expectativa) de diálogo com o outro, ausente no momento da produção, mas que se interessará, ou não, pelo enunciado captado, devolvendo-nos a resposta, esperada ou não. $\mathrm{E}$ isso, de alguma forma, é do conhecimento intuitivo do aluno. Não fica difícil, assim, suspeitar a dimensão do desânimo que dá àquele que tem que fažer de conta que quer dižer algo a alguém que ( $j a ́$ sabe de antemão) pouco se importa com o que ele dir, mas com o como ele div, quando se importa.

Evidentemente que não podemos generalizar, todavia, só trazemos à baila o dizer do aluno escrevente, só permitimos que ele, o dizer, nos incomode, se tivermos interesse, de fato, pela vida de nosso aluno. Na vida, evitamos dialogar com pessoas desagradáveis ou que nos são desinteressantes: ou elas, ou seu dizer. Em suma, nossa análise nos faz perceber que ainda lidamos com a produção 
de texto como uma atividade mecânica, já que não há espaço em nossos interesses ao discurso do aluno, considerando que, segundo Ruiz, a leitura feita pelo professor, via correção, não é [em momento algum] a mesma que a leitura realizada por um leitor comum (RUIZ, 2001, p. 48). Esforçamo-nos por tratar o texto do aluno como um objeto sagrado: se não para reconhecer seu domínio da ortografia e dos usos adequados da pontuação e concordância, ou ainda de sua fidelidade ao tema, mas para analisar como ele consegue amarrar seu texto de forma a dar-lhe um sentido, sentido este que não nos interessa, pois concebemos, na prática, o aluno como uma cabeça oca. Alguns ainda diriam: não é cabeça oca, pois ela está cheia de tudo o que já estamos carecas de saber. Mas, se diálogo é provocar o outro a uma participação no dito...

As experiências negativas e positivas por que passamos é que nos fizerem refletir e mudar nossa visão de produção de texto e nossa prática de sala de aula. Daí o interesse em socializá-la, na tentativa de contribuir para o tratamento dado à questão.

\section{EXPERENCIANDO O DIÁLOGO COM O DIZER DO OUTRINHO}

Ao palestrar sobre os interesses do Movimento dos Trabalhadores Sem-Terra-MST, Stedile (apud CHEVITARESE, 2002, p. 240-241), líder do movimento, declara:

nós procuramos incorporar na nossa organização o valor da mística, que para nós é a forma de organizar o sentimento coletivo; e o sentimento não tem razão (...) ele aglutina pessoas através de símbolos (...) de práticas pedagógicas, de posturas sociais...

O sentimento que, segundo Stedile, move montanhas e impulsiona ideiais (p. 240) é sempre bem vindo a uma prática pedagógica que foge ao mecanicismo e à artificialidade. Penso ter sido isso que nos fez experenciar uma relação diferente com os textos dos alunos. $\mathrm{O}$ aluno precisa sentir que seu texto vale, que o professor tem interesse 
por suas idéias, mesmo infantis, mesmo podendo estas não serem novidades para o professor.

\section{DIRETO AO PONTO}

Marcos ${ }^{1}$, como muitos de seus colegas, era um aluno de $6^{a}$ série, muito falante, mas com uma particularidade: na escrita, era muito sucinto, indo direto ao assunto. Seus interesses não diferiam dos garotos de sua idade. Como aprendera a ver a escrita como uma modalidade de comunicação, tinha oportunidade de comunicar em seus textos sua subjetividade, expectativas e frustrações, críticas e defesas ao que o circundava. No momento de socializar para a turma seu dizer, não ficava inibido, pois desde a $5^{\mathrm{a}}$ série sabia que não escrevia apenas para a professora.

Beto ${ }^{2}$ passou a ser nosso aluno somente a partir da $6^{\text {a }}$ série, tinha ojeriza à palavra redação. Para ele era um labor inútil. Ao perguntar-lhe, certa vez, se não iria participar "daquele momento", respondeu-nos perguntando se poderia escrever o que quisesse, o que estava sentindo. Dissemos que sim. No momento da socialização do texto, agradecemos, juntamente com a turma, a crítica que fez, por escrito, acerca da atividade - para ele, sem propósito - e tentamos argumentar a favor da prática. Percebendo que nos incomodou o que havia dito, na semana seguinte mostrounos um livro que estava lendo $O$ mundo de Sofia, justificou a atitude: sabe, fessora, depois que a senhora deu bola pro que escrevi, fiquei interessado pela atividade; conversei com papai e ele me deu esse livro... que vai me ajudar a pensar melhor sobre as coisas...

É interessante notar que Beto ${ }^{3}$ percebeu que não basta dizer, mas que o como dizer facilita ou não o entendimento acerca do que se diz. Essa relação parece que já estava impregnada nele. Daí, talvez, a razão de recorrer a suportes. Penso que o nosso maior esforço é convencer o aluno disso sem mecanicismo.

Carlão ${ }^{4}$, numa semana em que não dedicamos tempo às produções individuais e às leituras dos textos, reclamou e cobrou o tempo para a "redação" (atividade discursiva na modalidade 
escrita), sendo apoiado por outros colegas. Isso nos fortaleceu o entendimento de que o aluno tem o que dizer e acredita que isso vale a pena ser dito. Só precisa o professor confirmar sua hipótese.

Desde a $5^{\text {a }}$ série iniciamos, sem nos dar conta, um trabalho dialógico com o texto do aluno. Evidentemente que usávamos de qualquer expediente que julgássemos motivador para sua discursividade através da escrita, mas o que conta aqui é o como interagíamos com seus textos. Não nos propomos a dar receitas infalíveis sobre como fazer o aluno escrever, nem apontar gêneros a serem priorizados, apenas procuraremos trazer à baila como procedemos e o que ficou de positivo na nossa avaliação.

Nesse primeiro segmento, trabalhamos com produções de textos que priorizavam o desenvolvimento de sua capacidade de descrever: a si mesmos, a família, a casa, a rua, a escola, a professora, os colegas, a sala de aula, a praça que mais freqüentavam, enfim, aquilo que achassem interessante para descrever, quer em prosa, quer em verso. $\mathrm{Na} 6^{\mathrm{a}}$, trabalhamos a capacidade de narrar: sua história, fatos marcantes de suas vidas ou que presenciaram, projeções, suas fantasias de vida boa e a dos outros, e outras situações, quer em texto humorístico, quer por mero relato, quer história de ficção, fosse parodiando, fosse compondo letra de música, entre outros gêneros. $\mathrm{Na} 7^{\mathrm{a}}$, eram instigados a discutir idéias, opinar, argumentar, contestar etc., por meio escrito. Vale dizer que, desde que iniciamos o trabalho nas três quintas séries, foi-nos informado que acompanharíamos os alunos nas séries seguintes. Na última série $e^{5}$ a $7^{a}$, os alunos não desperdiçavam a oportunidade para manifestar sua versão da vida, com seus conflitos, anseios, idealizações, preconceitos e contradições.

Através de textos de alunos, pudemos sentir mais de perto o sofrimento de quem enfrentava a separação dos pais; perceber as fragilidades e expectativas próprias dos adolescentes, o despertar do namoro, da paquera; compreender algumas razões da auto-estima muito elevada de uns e muito baixa de outros. E por que a escrita não era um terror para a quase maioria? Por que era um momento 
de diálogo (BAKHTIN, 1997) à distância com a professora, que respondia à provocacãa, e com os colegas no momento da socialização. Alguns, é verdade, eram anarquizados por certos colegas irônicos que desdenhavam de suas histórias, opiniões, sonhos, vivências etc.. No entanto, isso só reforçava que não escreviam para o nada ou apenas para o professor [ter sua] redação [para corrigir] como tarefa de "caca erros" (RUIZ, 2001, p. 47). Tinham um (uns) interlocutor (es) atento (s) ao seu dizer; evidentemente, também, ao seu modo de dizer, pois havia momento em que salientávamos suas habilidades e deficiências, mas, como o conhecimento já nos era percebido como construção, víamos como natural a manifestação das deficiências, pois só assim poderiam ser reconhecidas e analisadas, inclusive por eles mesmos, a fim de serem superadas ou minimizadas.

Vale reconhecer que nesse período não estávamos isentas dos conflitos por que passam muitos professores, como, por exemplo, a indagação: $e$ a conclusão do programa? Entretanto, a participação quase que espontânea da maioria dos alunos nos fazia enfrentar a consciência confiantemente, priorizando no ensino da língua materna o trabalho com o texto verbal e não-verbal, oral e escrito.

Destaque-se aqui que a valorização do texto do aluno, mormente no ensino fundamental, é crucial para que este veja a prática de produção de texto escritos como uma atividade dialógica, dinâmica, com objetivos concretos.

\section{CONSIDERAÇÕES FINAIS}

Para concluir, gostaríamos de ressaltar que há trabalhos com a producão de texto em sala de aula até mais eficazes. todavia. nosso intuito foi o de chamar a atenção para o lado prático e muitas vezes esquecido dessa atividade, isto é, se tratada como uma atividade discursiva, como de fato é, teremos mais condições de desmitificá-la para o estudante, que, como aluno, não deixou de ser um praticante da linguagem, um usuário da língua, alguém cheio de coisas a dizer, mesmo sem muita importância para outros. Ele só espera a retro-alimentação, ou seja, encontrar alguém disposto 
a ouvir/ ler e dialogar com seu dizer, mais que unicamente com seu modo ${ }^{6}$ de dizer. Lidar com a discursividade em sala de aula é lidar com sentimentos, também.

\section{NOTAS}

${ }^{1}$ Nome fictício.

${ }^{2}$ Nome fictício.

${ }^{3}$ Nome fictício.

${ }^{4}$ Nome fictício.

${ }^{5}$ Esta foi a última série em que acompanhamos os alunos, pois o segmento de $5^{\mathrm{a}}$ a $8^{\mathrm{a}}$, nesse período, foi finalizado nesta escola, o que vinha sendo protelado havia tempo, por mudanças no projeto institucional.

${ }^{6} \mathrm{~A}$ palavra modo aqui não deve ser entendida da forma que a Análise do Discurso a toma, mas sim como a Gramática Normativa a concebe.

\section{REFERÊNCIAS}

